\title{
BMJ Open Non-invasive ventilation in the palliative care of patients with chronic obstructive pulmonary disease: a scoping review protocol
}

Simen A Steindal (D) , ${ }^{1,2}$ Kristin Hofs $ø,{ }^{1,3}$ Hanne Aagaard, ${ }^{1}$ Kari L Mariussen, ${ }^{1}$ Brith Andresen, ${ }^{1,4}$ Vivi L Christensen, ${ }^{5}$ Kristin Heggdal, ${ }^{1}$ Marte-Marie Wallander Karlsen, ${ }^{1}$ Monica E Kvande, ${ }^{1}$ Nina Margrethe Kynø, ${ }^{6}$ Anne Kathrine Langerud, ${ }^{1}$ Mari O Ohnstad, ${ }^{1}$ Kari Sørensen, ${ }^{1}$ Marie Hamilton Larsen ${ }^{1}$

To cite: Steindal SA, Hofs $\emptyset$ K, Aagaard $\mathrm{H}$, et al. Noninvasive ventilation in the palliative care of patients with chronic obstructive pulmonary disease: a scoping review protocol. BMJ Open 2021;11:e048344. doi:10.1136/ bmjopen-2020-048344

- Prepublication history and additional supplemental material for this paper are available online. To view these files, please visit the journal online (http://dx.doi.org/10.1136/ bmjopen-2020-048344).

Received 22 December 2020 Accepted 12 November 2021

D) Check for updates

(c) Author(s) (or their employer(s)) 2021. Re-use permitted under CC BY-NC. No commercial re-use. See rights and permissions. Published by BMJ.

For numbered affiliations see end of article.

Correspondence to

Simen A Steindal;

simen.alexander.steindal@ Idh.no

\section{ABSTRACT}

Introduction Patients with advanced chronic obstructive pulmonary disease (COPD) experience a great symptom burden. Breathlessness is a very frequently reported symptom that negatively affects all aspects of daily life and could lead to fear of dying. Non-invasive ventilation (NIV) could be an important palliative measure to manage breathlessness in patients with advanced COPD. We decided to conduct a scoping review to attain an overview of the existing research and to identify knowledge gaps. This scoping review aims to systematically map published studies on the use of NIV in the palliative care of COPD patients, including the perspectives and experiences of patients, families and healthcare professionals.

Methods and analysis This scoping review will employ the framework of Arksey and 0'Malley. The reporting will be guided by the Preferred Reporting Items for Systematic Reviews and Meta-Analyses extension for Scoping Reviews checklist. A comprehensive and systematic search strategy will be developed in cooperation with an experienced librarian. Database searches will be conducted in AMED, PEDro, Embase, CINAHL, PsycInfo and MEDLINE in February 2021. Pairs of authors will independently assess studies' eligibility and extract data using a standardised datacharting form. The data will be inductively summarised and organised thematically. The results will be discussed with an advisory board consisting of nurses and physicians from respiratory and intensive care units.

Ethics and dissemination Approval for the workshop with the advisory board has been attained from the Norwegian Centre for Research Data (480222), and approval will be attained from the Personal Data Protection Officers of the participating hospitals. All advisory board participants will sign an informed written consent before participation. The results could contribute to developing the body of evidence on the use of NIV in the palliative care of COPD patients and serve to identify directions for future research.

\section{INTRODUCTION}

Palliative care is an approach that aims to improve the quality of life and alleviate
Strengths and limitations of this study

- The scoping review will be conducted according to an acknowledged framework and will be guided by the Preferred Reporting Items for Systematic Reviews and Meta-Analyses extension for Scoping Reviews checklist.

- The search strategy will be built in cooperation with an experienced librarian and will be peer-reviewed by a second librarian using the Peer Review of Electronic Search Strategies checklist.

- Pairs of authors will independently assess studies' eligibility and extract data using a standardised data-charting form.

- The database searches will be limited by language restrictions, and grey literature will be excluded; therefore, the results may be affected by information bias.

- In line with the framework of Arksey and O'Malley, the methodological quality of the included studies will not be appraised, and policy and practice recommendations should be interpreted with caution.

burdensome symptoms of people living with life-limiting illnesses. ${ }^{1}$ Initially, palliative care focused on the care of dying cancer patients but has in recent years expanded to include other illnesses, such as chronic obstructive pulmonary disease (COPD). ${ }^{2}{ }^{3}$ The unpredictable illness trajectory of COPD makes it difficult to implement palliative care based on prognostication. ${ }^{4}$ Consequently, palliative care should be provided according to patients' needs and along with diseasemodifying therapies. ${ }^{4-6}$

Patients with advanced COPD suffer from a heavy symptom burden. Breathlessness, fatigue, anxiety and depression are frequently reported symptoms ${ }^{7}$ that may result in poor quality of life. ${ }^{8}$ Breathlessness is the most 
common and distressing symptom in patients with advanced COPD and may affect their ability to perform daily life activities, such as eating, dressing, sleeping, walking or socialising. ${ }^{89}$ Breathlessness related to acute exacerbation of COPD may be experienced as grave danger, which gives rise to anxiety and may be perceived as danger of dying, potentially leading to catastrophic thoughts. ${ }^{10}$ The fear of breathlessness and suffocation may instil fear of dying in patients with advanced COPD. ${ }^{8}$ Some patients feel that there is nothing that healthcare professionals can do to alleviate their breathlessness at the end of life. ${ }^{11}$

\section{Use of NIV treatment in palliative care of patients with COPD}

Non-invasive ventilation (NIV) is the standard of care for reducing morbidity and mortality rates in patients hospitalised with COPD exacerbation and acute respiratory failure ${ }^{12}$ Home NIV is often used in patients with COPD and chronic hypercapnic respiratory failure. ${ }^{13}$ Furthermore, NIV seems to be used in approximately $33 \%$ of COPD patients with poor life expectancy ${ }^{14}$ and may be appropriate for alleviating severe breathlessness. ${ }^{12} 1315$ It may reduce the severity of breathlessness by improving ventilation, oxygenation and the resistive load on the ventilatory muscles and reducing the work of breathing. ${ }^{12}{ }^{16}$ An online survey of physicians involved in home NIV treatment revealed that the main expected benefits of NIV for COPD patients were a reduction in hospital admissions, improvement in quality of life and relief of breathlessness. ${ }^{17}$

A study showed that key barriers to the delivery of palliative care for COPD patients included a reluctance to negotiate end-of-life decisions and a perceived lack of understanding among patients and their relatives regarding the illness trajectory. ${ }^{18}$ Overall, knowledge of relatives' perspectives on NIV treatment in palliative care and their role in the decision-making process appears to be limited. Thus, the family burden, satisfaction and views on NIV as an alternative to life-sustaining therapy need to be further explored to gain a comprehensive picture of the use of NIV in palliative care.

Curtis $e t a l^{19}$ grouped the use of NIV in patients with acute respiratory failure under three categories: (1) as life support with no present limitations on life-sustaining treatments, (2) as life support for patients and relatives who have decided to forgo invasive ventilation and (3) as a palliative measure for patients and relatives who have chosen to forgo all life support, receiving comfort measures only. ${ }^{19}$ In the latter two categories, the relief of breathlessness is particularly important. However, such use of NIV is controversial, ${ }^{4}$ as it may prolong the dying process. ${ }^{15}$ Furthermore, concerns have been raised regarding whether patients and relatives have had a discussion with healthcare professionals and fully understand the goals of care when NIV is used in the palliative care setting. ${ }^{20}$ A recent population-based cohort study ${ }^{21}$ studying trends in NIV use among older hospitalised adults with terminal respiratory failure, found a substantial increase in NIV use in the past two decades. These results may indicate a major shift in the way clinicians provide ventilatory support in the palliative phase. This study also underscores that high-quality evidence supporting use of NIV at the end of life remains elusive. Hence, there is a need for further studies to inform discussions about the goals of palliative NIV treatment between clinicians, the patients with for example COPD and their relatives.

\section{Previous research to support NIV treatment}

Previous systematic reviews and meta-analyses have examined the association of home NIV in COPD patients with clinical outcomes. ${ }^{22}{ }^{23}$ Wilson, et $a l^{22}$ found that the use of home NIV with bilevel positive pressure ventilation was associated with lower risks of mortality and hospital admissions compared with no home NIV but did not differ significantly from the latter in terms of quality of life. $^{21}$

Another systematic review and meta-analysis of randomised controlled trials (RCTs) evaluated the impact of NIV on mortality in all acute settings. ${ }^{24}$ The authors concluded that NIV improves survival in acute care settings but that the benefit could be lost if applied late in the illness trajectory as a rescue treatment. However, this review included several patient groups and did not include the palliative care setting. Another systematic review investigated the impact of NIV on breathlessness in inpatients with acute exacerbation of COPD and respiratory failure. The results were inconclusive due to methodological or reporting limitations of the included RCTs. ${ }^{25}$

Few systematic reviews have examined the use of NIV in palliative care. A systematic review and meta-analysis examined the use of NIV in patients with acute respiratory failure with do-not-intubate or comfort-measuresonly orders. The pooled results showed that $56 \%$ of the patients with do-not-intubate orders survived to be discharged from hospital and 32\% survived at 1 year. Moreover, NIV in patients with comfort-measures-only orders was associated with slightly lower breathlessness scores and opioid requirements compared with standard oxygen treatments. ${ }^{26}$ However, the included studies were not exclusively on COPD patients. An earlier integrated review examined interventions for supporting a palliative care approach in COPD patients. ${ }^{15}$ The results indicated that NIV may alleviate breathlessness and hypercapnia when combined with long-term oxygen treatment. Most studies examining NIV in end-stage COPD have focused on the avoidance of intubation rather than symptom relief. A recent systematic review on NIV in palliative care indicated that NIV may improve breathlessness and quality of life in patients with end-stage lunge diseases. ${ }^{27}$ However, this review was not limited to patients with COPD and only included quantitative studies, such as RCTs and prospective studies. Moreover, it had several important limitations; it is not clear whether the study selection process was performed by two authors independently and how the results were synthesised. 
The findings regarding the use of NIV in palliative care are conflicting, ${ }^{4}$ and previous systematic reviews only included quantitative studies. Consequently, conducting a comprehensive literature review (such as a scoping review) that includes various study designs, as well as the perspectives and experiences of patients, relatives and healthcare professionals, seems important for summarising the entire range of studies and existing findings. This could nuance and develop the body of evidence on this topic. Furthermore, such a review could identify gaps in the literature and new areas of enquiry and prepare the ground for a full systematic review. ${ }^{28}$

\section{Study aim and research question}

To the best of our knowledge, no scoping review has mapped the existing studies on the use of NIV in the palliative care of COPD patients. Therefore, this scoping review aims to systematically map published studies on the use of NIV in palliative care to answer the following research question: What is known about the use of NIV in palliative care from the perspectives and experiences of patients, relatives and healthcare professionals?

\section{METHODS AND ANALYSIS}

This scoping review will use the framework established by Arksey and O'Malley. ${ }^{28}$ This framework includes the following stages: identifying the research question; identifying relevant studies; study selection; charting the data and collating, summarising and reporting the results. An optional stage consultation exercise will be performed. The reporting of the scoping review will be guided by the Preferred Reporting Items for Systematic Reviews and Meta-Analyses extension for Scoping Reviews (PRISMA-ScR) checklist. ${ }^{29}$

\section{Eligibility criteria}

The Sample, Phenomenon of Interest, Design, Evaluation and Research Type (SPIDER) framework ${ }^{30}$ will be used to describe the inclusion and exclusion criteria, which are presented in table 1 .

\section{Information sources and search}

To identify relevant studies published in peer-reviewed journals, the databases Allied and Complementary Medicine (AMED), Physiotherapy Evidence Database (PEDro),

Table 1 Inclusion and exclusion criteria using the Sample, Phenomenon of Interest, Design, Evaluation and Research Type (SPIDER) framework

\begin{tabular}{|c|c|c|}
\hline & Inclusion & Exclusion \\
\hline Sample (S) & $\begin{array}{l}\text { Papers including patients with chronic obstructive pulmonary } \\
\text { disease (COPD) aged } 18 \text { years or older in a palliative care } \\
\text { trajectory, including advanced, late-stage and end-stage } \\
\text { COPD and do-not-resuscitate or comfort-measures-only } \\
\text { orders. } \\
\text { Papers including relatives of COPD patients in need of } \\
\text { palliative care. } \\
\text { Papers including healthcare professionals (HCPs) caring for } \\
\text { COPD patients in a palliative care trajectory. } \\
\text { Studies will be included regardless of reasons for or length of } \\
\text { non-invasive ventilation (NIV) treatment. }\end{array}$ & $\begin{array}{l}\text { Papers including patients younger than } \\
18 \text { years and all patients who are not in a } \\
\text { palliative care trajectory. } \\
\text { Papers including relatives of patients who } \\
\text { are not in a palliative care trajectory. } \\
\text { Papers including HCPs caring for patients } \\
\text { who are not in a palliative care trajectory. } \\
\text { Papers including patients without a COPD } \\
\text { diagnosis. }\end{array}$ \\
\hline $\begin{array}{l}\text { Phenomenon of } \\
\text { Interest }(\mathrm{PI})\end{array}$ & $\begin{array}{l}\text { Studies related to NIV treatment, including mask, intermittent } \\
\text { positive-pressure ventilation, bilevel positive airway pressure } \\
\text { and continuous positive airway pressure, in all healthcare } \\
\text { settings and in all phases of the palliative care trajectory. } \\
\text { Studies will be included if the COPD patients have been } \\
\text { treated with NIV in palliative care, regardless of the reasons } \\
\text { for or length of NIV treatment. }\end{array}$ & $\begin{array}{l}\text { Use of NIV with a curative intention. } \\
\text { Studies exploring other respiratory } \\
\text { interventions or treatment exercises } \\
\text { and studies focusing on other palliative } \\
\text { measures. } \\
\text { Studies including diseases other than } \\
\text { COPD. }\end{array}$ \\
\hline Design (D) & $\begin{array}{l}\text { Studies with qualitative, quantitative or mixed-methods } \\
\text { designs. }\end{array}$ & \\
\hline Evaluation (E) & $\begin{array}{l}\text { Perspectives and experiences of COPD patients, relatives } \\
\text { and HCPs regarding NIV in palliative care. }\end{array}$ & $\begin{array}{l}\text { Studies exploring the experiences and } \\
\text { perspectives of students. } \\
\text { Studies investigating patients', relatives' } \\
\text { or HCPs' experiences of specific } \\
\text { interventions or treatments. }\end{array}$ \\
\hline Research type (R) & $\begin{array}{l}\text { All research types of studies published in German, Spanish, } \\
\text { Swedish, Danish, Norwegian or English. }\end{array}$ & $\begin{array}{l}\text { Case studies, case-control studies, } \\
\text { reviews of any type, clinical guidelines and } \\
\text { master's and PhD theses. } \\
\text { Grey literature, such as conference } \\
\text { proceedings and abstracts, letters, } \\
\text { comments, editorials and non-peer- } \\
\text { reviewed articles. }\end{array}$ \\
\hline
\end{tabular}


Embase, Cumulative Index to Nursing and Allied Health Literature (CINAHL), PsycInfo and Medical Literature Analysis and Retrieval System Online (MEDLINE) will be searched from inception to February 2021. We opted to set no limit on the year of publication, as we aim to describe the entire range of research pertinent to our research question. ${ }^{31}$ The search will be updated approximately 2 months prior to publication.

In collaboration with the first and last author, an experienced librarian will build a comprehensive and systematic search strategy in MEDLINE using medical subject headings and text words. The search strategy will be discussed with the rest of the research group and tested. A second librarian will peer-review the search strategy using the Peer Review of Electronic Search Strategies (PRESS) checklist. ${ }^{32}$ The final search strategy in MEDLINE, shown in online supplemental material 1 , will be adopted for the other databases. The database search will be limited to articles published in German, Spanish, Swedish, Danish, Norwegian and English, as the authors understand only these languages and lack funding for translation of papers in other languages. Publication type filters will be used to exclude conference abstracts, comments, editorials and letters according to the functionality of each database to ensure that only studies published in peer-reviewed journals are included.

Manual searches will be conducted to screen the reference lists of the included articles. Forward tracking (citation searches) could also yield additional studies that will not be used; however, by conducting the entire search a second time no more than 2 months prior to publication, these studies will most probably be found without using this technique.

\section{Selection of the sources of evidence}

The librarian will export the search results to EndNote for duplicate removal. The search results will then be exported to Covidence (covidence.org), a web-based systematic review application, to facilitate storage and blinding of the screening of titles, abstracts and full-text papers. Seven pairs of authors will independently assess whether titles and abstracts and then full-text papers meet the eligibility criteria (table 1 ). In cases of disagreement, a third author (SAS, KH, HA or MHL) will conduct an independent assessment, and a final decision will be made based on consensus among the three authors. The reasons for excluding full-text papers will be recorded. The PRISMA flow diagram will be used to illustrate the study selection process.

\section{Data charting}

A standardised data-charting form will be developed using the SPIDER framework, and the following data will be extracted: author, year of publication and country; setting; sample (S); phenomenon of interest (PI); design (D); evaluation (E); research type (R) and NIV-related findings. The data-charting form will be pilot tested prior to data extraction by two pairs of authors (SAS and $\mathrm{KH}$, and $\mathrm{HA}$ and MHL), who will independently extract data from five of the included papers. Based on the experiences drawn from the pilot testing, the datacharting form may be revised. The data extraction will be conducted independently by pairs of authors. In cases of disagreement, a third author (SAS, KH, HA or MHL) will conduct an independent data extraction, and the final decision will be based on consensus among the three authors.

\section{Synthesis of results}

Unlike a systematic review, a scoping review does not aim to synthesise the findings. However, it requires an analytical framework to provide a narrative account of the included studies. The data will be inductively summarised and organised thematically. ${ }^{27}$ The extracted NIV-related findings will be read several times to identify patterns of similarities and differences in perspectives and experiences regarding the use of NIV in palliative care across the included studies. The identified patterns will be grouped thematically. The first, second, third and last author will analyse the data. All authors will discuss the emerging patterns and agree on the final thematic grouping. ${ }^{33}$ The results may be revised based on feedback during the consultation exercise (see the 'Consultation exercise' section).

\section{Consultation exercise}

To enhance our scoping review and make the results more useful and relevant for clinical practice, ${ }^{28}$ we will perform a consultation exercise. This means applying the optional sixth stage of the framework by Arksey and $\mathrm{O}$ Malley $^{28}$ and thereby incorporate a knowledge translation component of scoping study methodology. ${ }^{34}$ The results will be discussed with an advisory board consisting of six to eight nurses and physicians from respiratory and intensive care units at a university and a community hospital who work with patients with COPD and NIV. If possible, service users from a COPD patient organisation will also join the advisory board. We will facilitate a $2-3$ hours workshop. In the workshop the first, second and last author of the scoping review will attend, presenting relevant preliminary results from stage 5 of the review and discuss the importance and novelty for clinical practice with the advisory board members. ${ }^{34}$ This meeting will be audio recorded and transcribed verbatim. The results from the advisory board meeting will be analysed using an inductive thematic analysis inspired by Braun and Clarke ${ }^{35}$ and integrated with the study findings and help to provide an effective dissemination strategy. This consultation exercise could therefore allow additional valuable insights to be gained from our results, increase the validity of the study outcomes ${ }^{34}$ and provide additional references for published studies. ${ }^{28}$

Patient and public involvement

No patient involved. 


\section{ETHICS AND DISSEMINATION}

Ethical approval of a regional committee for medical and health research ethics or approval of the data protection officer or the university college is not required since this is a protocol for a scoping review. We will only use data from already published studies and will not collect any primary empirical data. The authors will not lose sight of the fact that this will be a secondary analysis. We will be consciously attentive to and respectful of the analysis and interpretation of data in the primary studies and thoroughly discuss how we can draw our conclusions. Approval for the workshop with the advisory board has been attained from the Norwegian Centre for Research Data (480222), and approval will be attained from the Personal Data Protection Officers of the participating hospitals. All advisory board participants will sign an informed written consent before participation.

The upcoming scoping review will include the perspectives and experiences of patients, relatives and healthcare professionals regarding the use of NIV in the palliative care of patients with COPD. This could improve the knowledge of this topic by identifying possible advantages, challenges, barriers and facilitators for such use of NIV. This review aims to identify gaps in the literature and new areas where a full systematic review could be conducted. The review is expected to be submitted to a peer-reviewed journal in autumn 2022.

\section{Author affiliations}

${ }^{1}$ Lovisenberg Diaconal University College, 0slo, Norway

${ }^{2}$ Faculty of Health Studies, VID Specialized University, Oslo, Norway

${ }^{3}$ Department of Research and Development, Division of Emergencies and Critical Care, Oslo University Hospital, Oslo, Norway

${ }^{4}$ The Department of Cardiothoracic Surgery, Rikshospitalet, Oslo University Hospital, Oslo, Norway

${ }^{5}$ Faculty of Health and Social Sciences, Department of Nursing and Health Sciences, University of South-Eastern Norway, Drammen, Norway

${ }^{6}$ Faculty of Health Sciences, Department of Nursing and Health Promotion, Acute and Critical IIIness, Oslo Metropolitan University, Oslo, Norway

\section{Twitter Simen A Steindal @SSteindal}

Acknowledgements We would like to acknowledge librarian Sara Clarke for peer reviewing our search strategy.

Contributors SAS and MHL were responsible for the design of this study. KML, SAS, and MHL developed the search strategy. SAS, KH, HA and MHL drafted the manuscript. SAS, KH, HA, KLM, BA, VLC, KH, M-MWK, MEK, NMK, AKL, MOO, KS and MHL approved the final version.

Funding The authors have not declared a specific grant for this research from any funding agency in the public, commercial or not-for-profit sectors.

Competing interests None declared.

Patient consent for publication Not required.

Provenance and peer review Not commissioned; externally peer reviewed.

Supplemental material This content has been supplied by the author(s). It has not been vetted by BMJ Publishing Group Limited (BMJ) and may not have been peer-reviewed. Any opinions or recommendations discussed are solely those of the author(s) and are not endorsed by BMJ. BMJ disclaims all liability and responsibility arising from any reliance placed on the content. Where the content includes any translated material, BMJ does not warrant the accuracy and reliability of the translations (including but not limited to local regulations, clinical guidelines, terminology, drug names and drug dosages), and is not responsible for any error and/or omissions arising from translation and adaptation or otherwise.
Open access This is an open access article distributed in accordance with the Creative Commons Attribution Non Commercial (CC BY-NC 4.0) license, which permits others to distribute, remix, adapt, build upon this work non-commercially, and license their derivative works on different terms, provided the original work is properly cited, appropriate credit is given, any changes made indicated, and the use is non-commercial. See: http://creativecommons.org/licenses/by-nc/4.0/.

ORCID iD

Simen A Steindal http://orcid.org/0000-0002-7676-8900

\section{REFERENCES}

1 World Health Organization. Definition of palliative care, 2020. Available: http://www.who.int/cancer/palliative/definition/en/ [Accessed 21 Apr 2021].

2 Kelley AS, Morrison RS. Palliative care for the seriously ill. N Engl J Med Overseas Ed 2015;373:747-55.

3 Maddocks M, Lovell N, Booth S, et al. Palliative care and management of troublesome symptoms for people with chronic obstructive pulmonary disease. The Lancet 2017;390:988-1002.

4 Lilly EJ, Senderovich H. Palliative care in chronic obstructive pulmonary disease. J Crit Care 2016;35:150-4.

5 Brown CE, Jecker NS, Curtis JR. Inadequate palliative care in chronic lung disease. An issue of health care inequality. Ann Am Thorac Soc 2016;13:311-6.

6 Radbruch L, De Lima L, Knaul F, et al. Redefining palliative Care-A new consensus-based definition. J Pain Symptom Manage 2020;60:754-64.

7 Moens K, Higginson IJ, Harding R, et al. Are there differences in the prevalence of palliative care-related problems in people living with advanced cancer and eight non-cancer conditions? A systematic review. J Pain Symptom Manage 2014;48:660-77.

8 Disler RT, Green A, Luckett T, et al. Experience of advanced chronic obstructive pulmonary disease: metasynthesis of qualitative research. J Pain Symptom Manage 2014;48:1182-99.

9 Giacomini M, DeJean D, Simeonov D, et al. Experiences of living and dying with COPD: a systematic review and synthesis of the qualitative empirical literature. Ont Health Technol Assess Ser 2012;12:1.

10 Harrison SL, Apps L, Singh SJ, et al. 'Consumed by breathing' - a critical interpretive meta-synthesis of the qualitative literature. Chronic IIIn 2014;10:31-49.

11 Gardiner C, Gott M, Payne S, et al. Exploring the care needs of patients with advanced COPD: an overview of the literature. Respir Med 2010;104:159-65.

12 Global initiative for obstructive pulmonary disease. Global strategy for prevention, diagnosis and management of COPD, 2020. Available: https://goldcopd.org/gold-reports/

13 Shah NM, D'Cruz RF, Murphy PB. Update: non-invasive ventilation in chronic obstructive pulmonary disease. $J$ Thorac Dis 2018;10:S71-9.

14 Davies JD. Noninvasive respiratory support at the end of life. Respir Care 2019;64:701-11.

15 Disler RT, Currow DC, Phillips JL, et al. Interventions to support a palliative care approach in patients with chronic obstructive pulmonary disease: an integrative review. Int $J$ Nurs Stud 2012;49:1443-58.

16 Ambrosino N, Fracchia C. Strategies to relieve dyspnoea in patients with advanced chronic respiratory diseases. A narrative review. Pulmonology 2019;25:289-98.

17 Crimi C, Noto A, Princi P, et al. Domiciliary non-invasive ventilation in COPD: an international survey of indications and practices. COPD 2016;13:483-90.

18 Spence A, Hasson F, Waldron M, et al. Professionals delivering palliative care to people with COPD: qualitative study. Palliat Med 2009;23:126-31.

19 Curtis JR, Cook DJ, Sinuff T, et al. Noninvasive positive pressure ventilation in critical and palliative care settings: understanding the goals of therapy. Crit Care Med 2007;35:932-9.

20 Scala R, Nava S. Niv and palliative care. Eur Respir Mon 2008;41:287-306.

21 Sullivan DR, Kim H, Gozalo PL, et al. Trends in noninvasive and invasive mechanical ventilation among Medicare beneficiaries at the end of life. JAMA Intern Med 2021;181:93-102.

22 Wilson ME, Dobler CC, Morrow AS, et al. Association of home noninvasive positive pressure ventilation with clinical outcomes in chronic obstructive pulmonary disease: a systematic review and meta-analysis. JAMA 2020;323:455-65. 
23 Dretzke J, Moore D, Dave C, et al. The effect of domiciliary noninvasive ventilation on clinical outcomes in stable and recently hospitalized patients with COPD: a systematic review and meta-analysis. Int $J$ Chron Obstruct Pulmon Dis 2016;11:2269-86

24 Cabrini L, Landoni G, Oriani A, et al. Noninvasive ventilation and survival in acute care settings: a comprehensive systematic review and metaanalysis of randomized controlled trials. Crit Care Med 2015;43:880-8.

25 Smith TA, Davidson PM, Lam LT, et al. The use of non-invasive ventilation for the relief of dyspnoea in exacerbations of chronic obstructive pulmonary disease; a systematic review. Respirology 2012;17:300-7.

26 Wilson ME, Majzoub AM, Dobler CC, et al. Noninvasive ventilation in patients with do-not-intubate and comfort-measures-only orders: a systematic review and meta-analysis. Crit Care Med 2018;46:1209-16.

27 Diaz de Teran T, Barbagelata E, Cilloniz C, et al. Non-invasive ventilation in palliative care: a systematic review. Minerva Med 2019;110:555-63.
28 Arksey H, O'Malley L. Scoping studies: towards a methodological framework. Int J Soc Res Methodol 2005;8:19-32.

29 Tricco AC, Lillie E, Zarin W, et al. PRISMA extension for scoping reviews (PRISMA-ScR): checklist and explanation. Ann Intern Med 2018;169:467-73.

30 Cooke A, Smith D, Booth A. Beyond PICO: the spider tool for qualitative evidence synthesis. Qual Health Res 2012;22:1435-43.

31 Pham MT, Rajić A, Greig JD, et al. A scoping review of scoping reviews: advancing the approach and enhancing the consistency. Res Synth Methods 2014;5:371-85.

32 McGowan J, Sampson M, Salzwedel DM, et al. PRESS Peer Review of Electronic Search Strategies: 2015 Guideline Statement. J Clin Epidemiol 2016;75:40-6.

33 Steindal SA, Nes AAG, Godskesen TE, et al. Patients' experiences of telehealth in palliative home care: Scoping review. J Med Internet Res 2020;22:e16218.

34 Levac D, Colquhoun H, O'Brien KK. Scoping studies: advancing the methodology. Implement Sci 2010;5:69.

35 Clarke V, Braun V. Using thematic analysis in psychology. Qual Res Psychol 2006;3:77-101. 